\title{
Influence d'une levure probiotique sur les bilans énergétiques et azotés de chèvres en début de lactation
}

\author{
S Giger-Reverdin 1, N Bezault 1, D Sauvant 1, \\ $N$ Lemaire 1, $F$ Ternois 1 , G Bertin 2 \\ 1 INRA, station de nutrition et alimentation de IINA-PG, \\ 16, rue Claude-Bernard, 75231 Paris cedex 05; \\ 2 Société OHF d'études et de participations, 94, rue Édouard-Vaillant, \\ 92306 Levallois-Perret, France
}

Une levure de type Saccharomyces cerevisiae dont les effets ruminaux ont été prouvés (Jouany et al, 1991) a été étudiée avec des chèvres en $1^{\mathrm{re}}, 2^{2 \theta}, 4^{\theta}$ et $6^{\theta}$ semaines suivant la mise bas. Le plan expérimental a permis de tester, suivant un plan factoriel $2 \times 2$ et la procédure de mesures répétées, sur 4 lots de 7 animaux, les effets liés à un apport de levure $\left(L=2,210^{9} \mathrm{CFU} / \mathrm{j} / \mathrm{animal}\right.$; $T=$ témoin), au niveau azoté de la ration $(N=108$ vs $\mathrm{B}=78 \mathrm{~g} \mathrm{PDI} / \mathrm{kg} \mathrm{MS}$ ), et à leur interaction. Les animaux recevaient une ration complète à base de pulpes de betteraves surpressées (50\%/MS), de foin de luzerne ( $25 \% / \mathrm{MS})$ et d'un aliment concentré $(25 \% / M S)$. Le concentré normal en azote (lots LN et TN) était constitué d'orge (20\%), de maïs $(10 \%)$, d'avoine $(20 \%)$ et de tourteau de soja $(50 \%)$; et celui bas en azote (lots LB et TB), d'orge $(40 \%)$, de maïs $(40 \%)$ et d'avoine $(20 \%)$.

L'ingestion d'énergie est statistiquement équivalente pour les 4 lots, et celle de PDI, significa- tivement plus élevée pour les lots LN et TN (tableau I). La levure a eu un effet significatif et positif sur le taux butyreux (effet moyen : $+4,5$ points), mais nul sur le taux protéique. L'effet positif de la levure sur la production laitière corrigée (PL35) est un peu plus marqué, quoique non significatif, avec le niveau azoté bas (LB/TB: $+35 \%$ vs $\mathrm{LN} / \mathrm{TN}:+13 \%)$. Toutes les chèvres ont présenté des bilans énergétique (BE) et azoté (BPDI) négatifs en moyenne, et l'apport de levure les a diminués significativement, principalement pour les niveaux azotés bas. La teneur plasmatique en AGNE conforte l'effet sur le BE et le taux butyreux. Les BPDI des chèvres des lots $L N$ et TN sont moins déficitaires que ceux des lots LB et $T B$, et leurs urémies plus fortes.

Jouany JP, Fonty G, Lassalas B, Dore J, Gouet P, Bertin G (1991) 21st Biennial Conference on Rumen Function, 21, 7

Tableau I. Influence de la levure sur les principaux paramètres zootechniques.

\begin{tabular}{|c|c|c|c|c|c|c|c|}
\hline & \multicolumn{4}{|c|}{ Lots } & \multicolumn{3}{|c|}{ Effets } \\
\hline & $L B$ & $T B$ & $L N$ & $T N$ & $N$ vs $B$ & $L$ vs $T$ & Interaction \\
\hline Énergie nelte ingérée (ENI) (kcal/kg P0,75) & $141^{a}$ & $143^{a}$ & $145^{a}$ & $139^{a}$ & NS & NS & NS \\
\hline PDI ingérées (PDI) $(g / \mathrm{kg} P 0,75)$ & $6,69^{a}$ & $6,82^{a}$ & $9,54^{b}$ & $9,24 b$ & 0,01 & NS & NS \\
\hline Bilan énergétique (BE) (kcal/kg P0.75) & $-65,3^{a}$ & $-25,5^{b}$ & $-64,2^{a}$ & $-56,4^{a}$ & NS & 0,02 & 0,09 \\
\hline Bilan PDI (BPDi) (g/kg P0,75) & $-4,91^{a}$ & $-2,33^{b}$ & $-2,21^{b}$ & $-1,35^{b}$ & 0,01 & 0,01 & NS \\
\hline \multicolumn{8}{|l|}{ Production laitière corrigée (PL35) } \\
\hline$(\mathrm{kg} / \mathrm{kg} \mathrm{P0,75})$ & $0,199^{a}$ & $0,147^{b}$ & $0,202^{a}$ & $0,178^{a, b}$ & NS & 0,04 & NS \\
\hline AGNE ( $\mu$ eq/L) & $585^{a, b}$ & $399^{b}$ & $712^{a}$ & $550^{\mathrm{b}}$ & 0,09 & 0,01 & NS \\
\hline Urémie $(g / L)$ & $0,291^{a}$ & $0,342^{a}$ & $0,535^{b}$ & $0,472^{b}$ & 0,01 & NS & 0,04 \\
\hline
\end{tabular}

